\title{
Article \\ Serum C-Reactive Protein and Interleukin-6 Levels as Biomarkers for Disease Severity and Clinical Outcomes in Patients with Idiopathic Granulomatous Mastitis
}

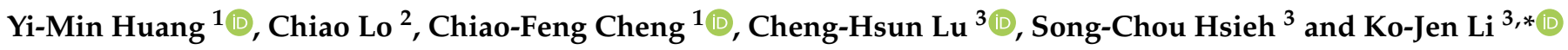 \\ 1 Department of Internal Medicine, National Taiwan University Hospital Yunlin branch, Yunlin 640, Taiwan; \\ ymwhuang@gmail.com (Y.-M.H.); chiaofengcheng@gmail.com (C.-F.C.) \\ 2 Department of Surgery, National Taiwan University Hospital, Taipei 100, Taiwan; dtsurgz6@gmail.com \\ 3 Department of Internal Medicine, National Taiwan University Hospital, Taipei 100, Taiwan; \\ b89401085@ntu.edu.tw (C.-H.L.); hsiehsc@ntu.edu.tw (S.-C.H.) \\ * Correspondence: dtmed170@gmail.com; Tel.: +886-2-2312-3456
}

Citation: Huang, Y.-M.; Lo, C.;

Cheng, C.-F.; Lu, C.-H.; Hsieh, S.-C.;

Li, K.-J. Serum C-Reactive Protein and Interleukin-6 Levels as Biomarkers for Disease Severity and Clinical Outcomes in Patients with Idiopathic Granulomatous Mastitis. J. Clin. Med. 2021, 10, 2077. https://doi.org/ $10.3390 / \mathrm{jcm} 10102077$

Received: 8 April 2021

Accepted: 7 May 2021

Published: 12 May 2021

Publisher's Note: MDPI stays neutral with regard to jurisdictional claims in published maps and institutional affiliations.

Copyright: (c) 2021 by the authors. Licensee MDPI, Basel, Switzerland. This article is an open access article distributed under the terms and conditions of the Creative Commons Attribution (CC BY) license (https:// creativecommons.org/licenses/by/ $4.0 /)$.

\begin{abstract}
Idiopathic granulomatous mastitis (IGM) is a rare inflammatory breast disease mimicking breast cancer. Limited research has been conducted on the application of serum biomarkers. This study aims to investigate the association of serum biomarkers with disease severity in patients with IGM. From November 2011 to March 2020, medical records of patients with IGM were reviewed. Serum cytokine levels were measured in patients and healthy controls between July 2018 and March 2020. A total of 41 patients with histologically proven IGM were found. Serum interleukin (IL)- 6 level was significantly higher in patients with IGM $(n=11)$ than healthy controls $(n=7)$. Serum IL-6 and C-reactive protein (CRP) levels were significantly higher in patients with severe disease than mild and moderate disease. Serum IL-6 (Spearman's $\rho=0.855 ; p<0.001$ ) and CRP (Spearman's $\rho=0.838 ; p=0.001$ ) levels were associated with time to resolution. A higher serum CRP level was associated with a longer time to resolution $(B=0.322 ; p<0.001)$ in multiple linear regression analysis. Serum IL-6 and CRP levels can be used as biomarkers for the evaluation of disease severity in IGM. IL-6 may play a crucial role in the immunopathology of IGM.
\end{abstract}

Keywords: C-reactive protein; disease severity; idiopathic granulomatous mastitis; interleukin-6; time to resolution

\section{Introduction}

Idiopathic granulomatous mastitis (IGM) is a rare, chronic, and benign breast disease, which is characterized by non-caseating granulomatous inflammation. It was first reported by Kessler and Wolloch in 1972, and the clinical and radiographic features can simulate breast cancer [1]. The common clinical manifestations include tender breast mass, skin erythema, ulcer, fistula, and abscess formation [2]. Extramammary manifestations are found in $34 \%$ of the patients with IGM [3]. The typical extramammary manifestations include arthritis and erythema nodosum [4]. IGM is found mainly in the Asian, North African, and Hispanics [3]. Women of childbearing age with a history of parity and breastfeeding are predominantly affected, whereas nulliparous women, postmenopausal women, and men are seldom reported [5]. Although the etiology of IGM is not fully established, factors contributing to the development of IGM include hormones, autoimmunity, microorganisms, smoking, and $\alpha 1$-antitrypsin deficiency [6].

The definite diagnosis of IGM requires histopathological examination and the exclusion of other etiologies [7]. The typical histopathological findings consist of well-formed or vague non-caseating granulomatous inflammation, epithelioid histiocytes, multinucleated giant cells, microabscess formation, and fibrosis (Figure 1). The infiltration of neutrophils, plasma cells, lymphocytes, and eosinophils can be found [8]. Based on the literature, surgical management or systemic glucocorticoid (GC) is widely considered as the initial 
treatment in IGM patients [3]. Moreover, topical GC, methotrexate (MTX), azathioprine, hydroxychloroquine, colchicine, and tumor necrosis factor (TNF) inhibitors have been reported to treat IGM [9-12].

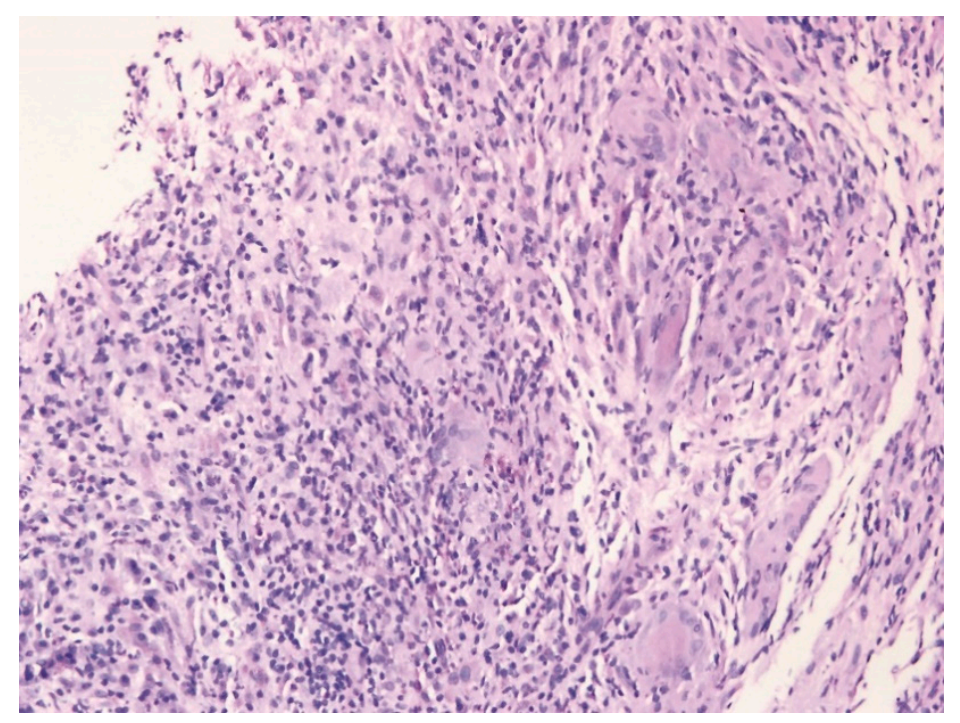

Figure 1. A histopathological examination showed vague non-caseating granulomatous inflammation with epithelioid histiocytes, lymphocytes, scattered neutrophils, and multinucleated giant cells in a patient with idiopathic granulomatous mastitis $(\mathrm{H} \& \mathrm{E} \times 200)$.

The localized inflammatory response has been considered as one of the pathogenic factors of IGM. This hypothesis is supported by the lymphocytes infiltration in pathological sections, effectiveness of GC treatment, and presence of extramammary manifestations [4]. Recent studies had also found higher serum concentrations of interleukin (IL)-8, IL-10, IL17, IL-22, IL-23, and IL-33 in IGM patients than healthy controls (HC) [13-15]. However, the association between clinical and immunological features of IGM remains unrevealed. This study aims to evaluate the association between serum biomarkers and clinical outcomes and investigate risk factors associated with treatment-refractory status.

\section{Materials and Methods}

\subsection{Patients}

From November 2011 to March 2020, medical records of patients with IGM at the National Taiwan University Hospital were retrospectively reviewed. Patients with histopathological evidence of IGM were included. Core-needle biopsy or excisional biopsy was performed for a definite diagnosis. Stains and cultures of pus or tissues were performed for bacteria, acid-fast organisms, and fungi. Patients with infection, malignancy, sarcoidosis, granulomatosis with polyangiitis, giant cell arteritis, and polyarteritis nodosa were excluded. Patients with previous pulmonary or extrapulmonary tuberculosis, contact history of patients infected with tuberculosis, pregnancy, silicone breast implants, and recent tetanus vaccination were also excluded.

\subsection{Serum Assays}

From July 2018 to March 2020, serum samples were measured in patients with IGM and HC. All samples had been stored at $-80{ }^{\circ} \mathrm{C}$ until further analysis was performed. The concentrations of TNF- $\alpha$, IL-1 $\beta$, IL-2, IL-4, IL-6, IL-10, IL-12p70, IL-17A, IL-22, IL23 , and granulocyte-macrophage colony-stimulating factor (GM-CSF) were measured with the ProcartaPlex magnetic bead-based multiplex assay (Cat. No. EPX180-12165-901; eBioscience, Vienna, Austria). The manufacturer's instructions were followed. The lower limit of detection for each cytokine was as follows: $0.4 \mathrm{pg} / \mathrm{mL}$ for TNF- $\alpha, 0.2 \mathrm{pg} / \mathrm{mL}$ for IL-1 $\beta, 0.8 \mathrm{pg} / \mathrm{mL}$ for IL-2, $1.5 \mathrm{pg} / \mathrm{mL}$ for IL-4, $0.4 \mathrm{pg} / \mathrm{mL}$ for IL-6, $0.1 \mathrm{pg} / \mathrm{mL}$ for 
IL-10, $0.04 \mathrm{pg} / \mathrm{mL}$ for IL-12p70, $0.1 \mathrm{pg} / \mathrm{mL}$ for IL-17A, 8.2 pg/mL for IL-22, $0.9 \mathrm{pg} / \mathrm{mL}$ for IL-23, and $1.2 \mathrm{pg} / \mathrm{mL}$ for GM-CSF. Values below the limit of detection were assumed to be one-half of the minimum detectable level for statistical and graphing purposes. All subjects were recruited according to a protocol approved by the Institution Review Board and Research Ethics Committees of National Taiwan University Hospital, Taipei, Taiwan (201705097RINB).

\subsection{Treatments}

Patients with IGM received initial management by experienced breast surgeons. Ultrasonography-guided fine needle aspiration was performed for breast abscess drainage. Surgical management was performed in patients with abscess formation or skin fistula after informed consent. Surgical management included incision and drainage, local excision, and partial mastectomy. As a result of cosmetic concerns, surgery was done in a minimally invasive manner. The benefits and risks of immunosuppressants were explained by experienced rheumatologists in a way that patients understood. Systemic GC was started in a shared decision-making approach. Dose tapering of systemic GC was initiated in the patients with significant treatment response after 2 weeks. Oral MTX was added to the patients who suffered from disease exacerbation during systemic GC dose reduction. MTX dosing was started at 7.5-10 mg weekly and increased to $15 \mathrm{mg}$ weekly according to treatment response and physician's judgments. Systemic GC was stopped gradually after the achievement of clinical resolution. Then, oral MTX was discontinued under sustained clinical resolution.

\subsection{Data Collection}

Information regarding patient demographics, clinical manifestations, obstetric history, serum C-reactive protein (CRP) level, treatment modalities, and clinical outcomes was obtained from medical records. Mild disease was defined as lesion size $<2 \mathrm{~cm}$, occasional mastalgia, and no abscess formation or skin ulcer; moderate disease was defined as lesion size less than 2-5 cm, small abscess formation with or without a skin fistula; severe disease was defined as lesion size $>5 \mathrm{~cm}$, refractory mastalgia, abscess formation requiring repeated drainage, and multiple skin ulcers and fistulas [16]. Laboratory data on the initial visit were analyzed. A clinical resolution was defined as a complete absence of symptoms [16-20]. Time to resolution was defined as the duration from initiation of medical or surgical management to the achievement of clinical resolution. Recurrence was defined as another episode of IGM after the achievement of clinical resolution of the initial episode for 3 months $[16,17,19,20]$.

\subsection{Statistical Analysis}

The characteristics of the IGM patients with mild, moderate, and severe disease were compared with a Kruskal-Wallis test for continuous variables or a Chi-square test for categorical variables. When the Kruskal-Wallis test was significant, post hoc Dunn's test was used to adjust for multiple comparisons to determine where differences existed. When the Chi-square test was significant, Fisher's exact test and Bonferroni correction were performed for the pairwise comparisons between three groups. The serum concentrations of cytokines were compared with Mann-Whitney U tests. Plots were generated to illustrate the association between time to resolution and serum biomarkers, and Spearman's correlation coefficients were computed. Before further analysis, each variable was examined for normal distribution by histogram and box plot. If a variable was not normally distributed, it was logarithmically transformed before the linear regression analysis. Time to resolution, body mass index, age of menarche, gestation, lesion size, and serum CRP level were transformed using the natural logarithm because of the skewed distribution. The association of time to resolution and clinical features was evaluated using simple linear regression analysis. Variables with $p<0.157$ were included in the exploratory backward multiple linear regression model [21]. The association of recurrence and clinical features 
was investigated using univariate logistic regression analysis. All tests were two-tailed and $p<0.05$ was considered statistically significant. Data analyses were conducted using SPSS software version 25.0 (SPSS Inc., Armonk, NY, USA).

\section{Results}

\subsection{Characteristics According to Disease Severity}

A total of 41 patients with histologically proven IGM were found from November 2011 to March 2020. Serum samples of 11 IGM patients and seven HC were collected. Clinical features and outcomes of IGM are presented according to disease severity (Table 1). Patients had a mean (SD) age of 35.9 (5.8) years and a median (IQR) lesion size of 4.0 $(2.1-5.1) \mathrm{cm}$. The median (IQR) time of follow-up was $24.0(14.5-42.5)$ months. Among the included patients, 20 (48.8\%) presented with abscess formation, 29 (70.7\%) presented with multiple lesions, 21 (51.2\%) presented with skin ulcer or fistula, nine (22.0\%) presented with bilateral lesions, and $11(26.8 \%)$ presented with extramammary manifestations. The median (IQR) CRP level was $0.56(0.14-2.89) \mathrm{mg} / \mathrm{dL}$. Thirty-six (87.8\%) patients were treated with systemic GC, $16(39.0 \%)$ were treated with oral MTX, and $14(34.1 \%)$ were treated with surgical management. All patients achieved clinical resolution during the study period. The median (IQR) time to resolution was 26.3 (12.4-56.0) weeks. Recurrence was found in nine $(22.0 \%)$ patients. The median (IQR) time from resolution to recurrence was 24.0 (3.0-27.0) months. Lesion size, percentage of multiple lesions, percentage of skin ulcer or fistula, CRP, and time to resolution were significantly different between the IGM patients with mild, moderate, and severe disease $(p<0.001, p<0.001, p=0.008, p<0.001$, $p=0.002$, respectively).

\subsection{IL-6 and CRP as Biomarkers for Disease Severity}

The serum concentrations of TNF- $\alpha$, IL-1 $\beta$, IL-2, IL-6, IL-12p70, and IL-17A were significantly higher in patients with IGM than HC (Table 2). Among these cytokines, serum IL-6 level was significantly different between the IGM patients $(p=0.016)$ with mild $(n=1)$, moderate $(n=4)$, and severe disease $(n=6)$. Patients with severe disease had higher serum IL-6 levels than moderate disease (median: 5.32 vs. $0.00 \mathrm{pg} / \mathrm{mL}$; adjusted $p=0.007$ ) (Figure 2a). Moreover, serum IL-6 had a positive correlation with time to resolution (Spearman's $\rho=0.855 ; p<0.001$ ) (Figure $2 b$ ). Among the patients with cytokine data, serum CRP level was positively correlated with serum IL-6 level (Spearman's $\rho=0.830 ; p=0.002$ ). Serum CRP level was higher in the patients with severe disease (median: $2.80 \mathrm{mg} / \mathrm{dL}$ ) than moderate disease (median: $0.26 \mathrm{mg} / \mathrm{dL}$; adjusted $p=0.032$ ) and mild disease (median: $0.08 \mathrm{mg} / \mathrm{dL}$; adjusted $p=0.041$ ) (Figure 2c). The CRP level also had a positive correlation with time to resolution (Spearman's $\rho=0.838 ; p=0.001$ ) (Figure 2d). 
Table 1. Clinical features, serum C-reactive protein level, treatment modalities, and outcomes of patients with idiopathic granulomatous mastitis according to disease severity.

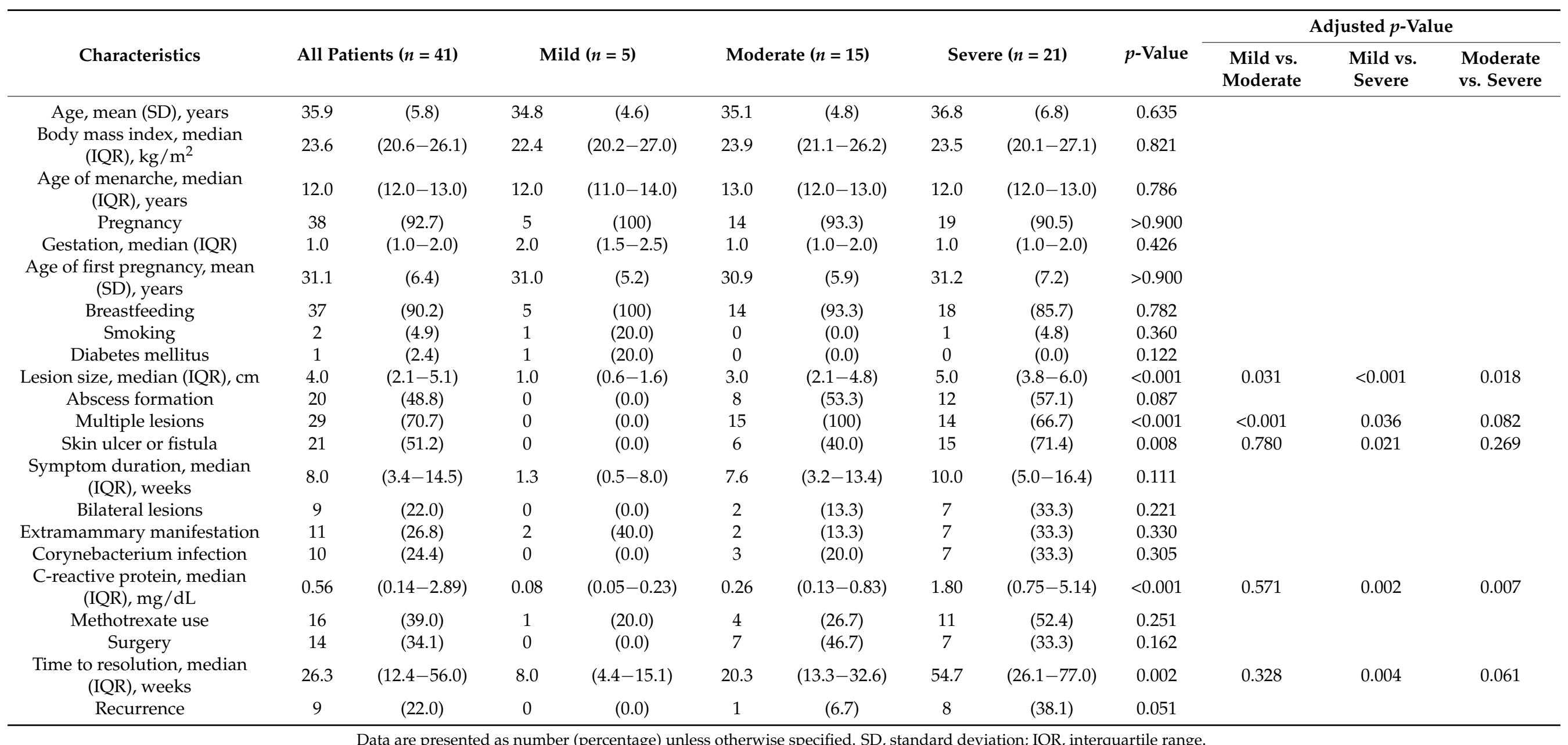


Table 2. The comparison of serum cytokine levels of patients with idiopathic granulomatous mastitis and healthy controls.

\begin{tabular}{|c|c|c|c|c|c|}
\hline \multirow{2}{*}{ Cytokines } & \multirow{2}{*}{\multicolumn{2}{|c|}{$\begin{array}{c}\text { IGM }(n=11) \\
\text { Median (IQR) }\end{array}$}} & \multirow{2}{*}{\multicolumn{2}{|c|}{$\begin{array}{c}\text { HC }(n=7) \\
\text { Median (IQR) }\end{array}$}} & \multirow{2}{*}{$p$-Value } \\
\hline & & & & & \\
\hline $\mathrm{TNF}-\alpha, \mathrm{pg} / \mathrm{mL}$ & 11.66 & $(8.70-24.11)$ & 7.21 & $(4.97-7.21)$ & $<0.001$ \\
\hline $\mathrm{IL}-1 \beta, \mathrm{pg} / \mathrm{mL}$ & 2.80 & $(1.59-3.52)$ & 0.21 & (N.D.-1.42) & $<0.001$ \\
\hline IL-2, pg/mL & 13.77 & $(3.97-22.08)$ & 2.63 & (N.D.-6.97) & 0.023 \\
\hline IL-4,pg/mL & & N.D. & & N.D. & N.A. \\
\hline IL-6, pg/mL & 3.89 & (N.D.-6.09) & & N.D. & 0.023 \\
\hline IL-10, pg/mL & 1.13 & $(0.55-1.59)$ & 1.06 & $(0.81-1.99)$ & 0.892 \\
\hline IL-12p70, pg/mL & 6.39 & $(6.24-6.98)$ & 6.10 & (5.95-6.10) & 0.016 \\
\hline IL-17A, pg/mL & 1.13 & $(0.41-1.98)$ & & N.D. & 0.041 \\
\hline $\mathrm{IL}-22, \mathrm{pg} / \mathrm{mL}$ & N.D. & (N.D.-14.29) & N.D. & (N.D.-48.66) & 0.885 \\
\hline IL-23, pg/mL & & N.D. & & N.D. & N.A. \\
\hline GM-CSF, pg/mL & N.D. & (N.D.-3.52) & & N.D. & 0.118 \\
\hline
\end{tabular}

IGM, idiopathic granulomatous mastitis; HC, healthy controls; IQR, interquartile range; TNF, tumor necrosis factor; IL, interleukin; N.D., not detectable; N.A., not applicable; GM-CSF, granulocyte-macrophage colonystimulating factor.

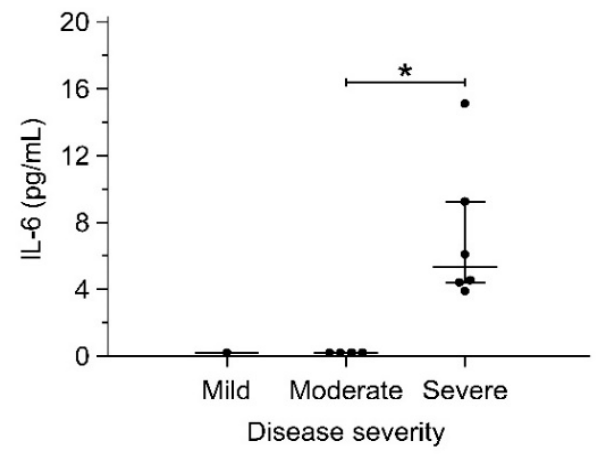

(a)

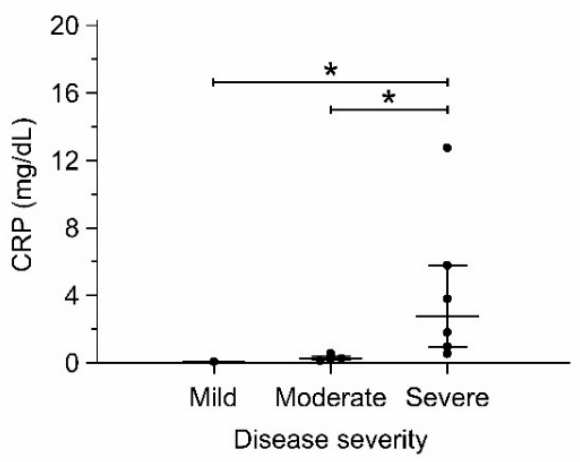

(c)

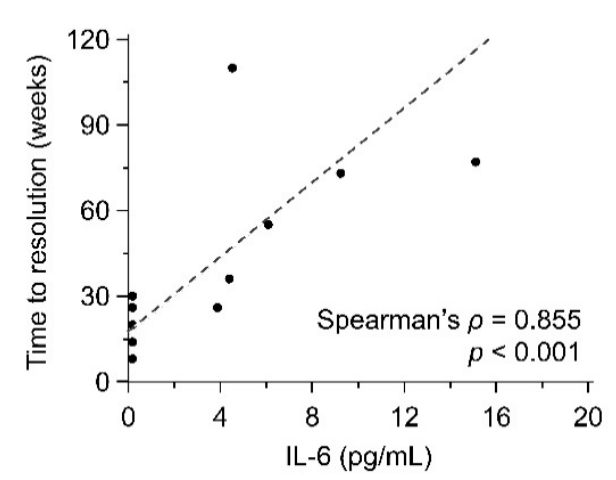

(b)

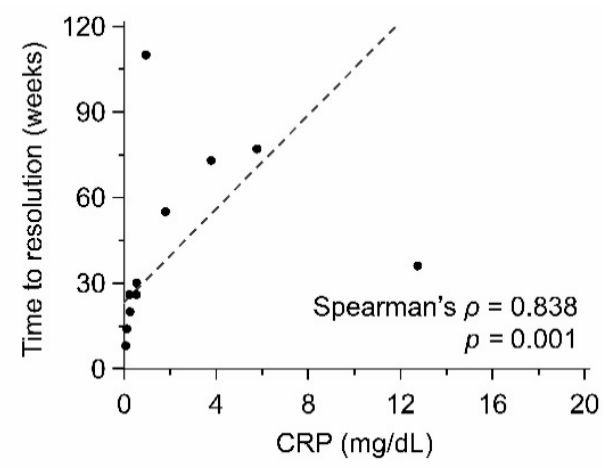

(d)

Figure 2. Serum IL-6 (a) and CRP (c) levels among IGM patients with mild, moderate, and severe disease were compared using the Kruskal-Wallis test and post hoc Dunn's test. Spearman's correlation coefficient was calculated to determine the correlation of serum IL-6 (b) and CRP (d) levels and time to resolution. Scatter diagrams and reduced major axis regression (dashed line) were displayed. ${ }^{*} p<0.05$; CRP, C-reactive protein; IGM, idiopathic granulomatous mastitis; IL-6, interleukin-6.

\subsection{Factors Associated with Time to Resolution}

Factors associated with time to resolution in IGM patients are outlined in Table 3. In simple linear regression analysis, time to resolution had a positive association with 
skin ulcer or fistula $(B=1.480 ; p<0.001)$, bilateral lesions $(B=1.325 ; p<0.001)$, serum CRP level $(B=0.404 ; p<0.001)$, and MTX use $(B=1.203 ; p<0.001)$, and it had a negative association with breastfeeding $(\mathrm{B}=-1.188 ; p=0.033)$ and smoking $(\mathrm{B}=-1.650 ; p=0.032)$. In exploratory backward multiple linear regression analysis, time to resolution was independently associated with breastfeeding $(\mathrm{B}=-0.724 ; p=0.040)$, bilateral lesions $(\mathrm{B}=0.549$; $p=0.047)$, serum CRP level $(B=0.322 ; p<0.001)$, and MTX use $(B=0.707 ; p=0.004)$ (Table 4).

Table 3. Factors associated with time to resolution in patients with idiopathic granulomatous mastitis.

\begin{tabular}{|c|c|c|c|c|c|c|}
\hline \multirow{2}{*}{ Characteristics $(n=41)$} & \multicolumn{6}{|c|}{ Simple Linear Regression } \\
\hline & \multicolumn{2}{|c|}{ Unstandardized B (SE) } & \multicolumn{3}{|c|}{$95 \%$ CI } & \multirow{2}{*}{$\begin{array}{c}p \text {-Value } \\
0.756\end{array}$} \\
\hline Age, years & -0.009 & $(0.029)$ & -0.069 & to & 0.050 & \\
\hline Body mass index, $\mathrm{kg} / \mathrm{m}^{2}$ & 0.064 & $(0.887)$ & -1.731 & to & 1.858 & $>0.900$ \\
\hline Age of menarche, years & 0.501 & $(1.542)$ & -2.618 & to & 3.621 & 0.747 \\
\hline Pregnancy & -1.012 & $(0.630)$ & -2.285 & to & 0.262 & 0.116 \\
\hline Gestation & 0.037 & $(0.332)$ & -0.636 & to & 0.710 & $>0.900$ \\
\hline Age of first pregnancy, years & 0.026 & $(0.028)$ & -0.030 & to & 0.082 & 0.345 \\
\hline Breastfeeding & -1.188 & $(0.538)$ & -2.276 & to & -0.100 & 0.033 \\
\hline Smoking & -1.650 & $(0.740)$ & -3.147 & to & -0.153 & 0.032 \\
\hline Diabetes mellitus & -1.175 & $(1.081)$ & -3.362 & to & 1.012 & 0.284 \\
\hline Lesion size, $\mathrm{cm}$ & 0.435 & $(0.287)$ & -0.146 & to & 1.015 & 0.138 \\
\hline Abscess formation & 0.417 & $(0.332)$ & -0.255 & to & 1.088 & 0.217 \\
\hline Multiple lesions & 0.674 & $(0.356)$ & -0.047 & to & 1.394 & 0.066 \\
\hline Skin ulcer or fistula & 1.480 & $(0.242)$ & 0.991 & to & 1.969 & $<0.001$ \\
\hline Symptom duration, weeks & 0.083 & $(0.129)$ & -0.179 & to & 0.345 & 0.525 \\
\hline Bilateral lesions & 1.325 & $(0.350)$ & 0.618 & to & 2.032 & $<0.001$ \\
\hline Extramammary manifestation & 0.466 & $(0.375)$ & -0.292 & to & 1.224 & 0.221 \\
\hline Corynebacterium infection & 0.666 & $(0.380)$ & -0.102 & to & 1.434 & 0.087 \\
\hline C-reactive protein, $\mathrm{mg} / \mathrm{dL}$ & 0.404 & $(0.071)$ & 0.260 & to & 0.548 & $<0.001$ \\
\hline Methotrexate use & 1.203 & $(0.289)$ & 0.619 & to & 1.787 & $<0.001$ \\
\hline Surgery & -0.131 & $(0.356)$ & -0.852 & to & 0.590 & 0.715 \\
\hline Recurrence & 0.784 & $(0.389)$ & -0.003 & to & 1.572 & 0.051 \\
\hline
\end{tabular}

$\mathrm{SE}$, standard error; $\mathrm{CI}$, confidence interval.

Table 4. Backward multiple linear regression model for prediction of time to resolution in patients with idiopathic granulomatous mastitis.

\begin{tabular}{ccccccc}
\hline \multirow{2}{*}{ Characteristics $(n=41)$} & \multicolumn{5}{c}{ Multiple Linear Regression (Backward) } \\
\cline { 2 - 7 } & \multicolumn{7}{c}{ Unstandardized B (SE) } & $\mathbf{9 5 \%}$ CI & $p$-Value \\
\hline Breastfeeding & -0.724 & $(0.339)$ & -1.414 & to & -0.034 & 0.040 \\
Smoking & -1.001 & $(0.489)$ & -1.898 & to & 0.091 & 0.074 \\
Bilateral lesions & 0.549 & $(0.266)$ & 0.008 & to & 1.089 & 0.047 \\
C-reactive protein, & 0.322 & $(0.086)$ & 0.148 & to & 0.497 & $<0.001$ \\
mg/dL & 0.707 & $(0.230)$ & 0.239 & to & 1.176 & 0.004 \\
Methotrexate use & -0.612 & $(0.322)$ & -1.266 & to & 0.042 & 0.066 \\
Recurrence & & & & & &
\end{tabular}

SE, standard error; CI, confidence interval.

\subsection{Factors Associated with Recurrence}

Factors associated with recurrence in IGM patients are outlined in Table 5 . In univariate logistic regression analysis, age (odds ratio (OR) 1.18; 95\% confidence interval (CI), $1.00-1.39 ; p=0.049$ ), skin ulcer or fistula (OR 11.69; 95\% CI, $1.30-105.03 ; p=0.028$ ) and serum CRP level (OR 1.87; 95\% CI, 1.14-3.08; $p=0.013$ ) were factors associated with recurrence. 
Table 5. Factors associated with recurrence in patients with idiopathic granulomatous mastitis.

\begin{tabular}{cccccc}
\hline Characteristics $(\boldsymbol{n}=\mathbf{4 1})$ & \multicolumn{3}{c}{ Univariate Logistic Regression } \\
\cline { 2 - 6 } & Odds Ratio & \multicolumn{3}{c}{$\mathbf{9 5 \%}$ CI } & $p$-Value \\
\hline Age, years & 1.179 & 1.000 & to & 1.390 & 0.049 \\
Body mass index, $\mathrm{kg} / \mathrm{m}^{2}$ & 0.969 & 0.827 & to & 1.135 & 0.697 \\
Age of menarche, years & 1.113 & 0.604 & to & 2.052 & 0.731 \\
Pregnancy & 0.533 & 0.043 & to & 6.655 & 0.625 \\
Gestation & 1.817 & 0.873 & to & 3.783 & 0.110 \\
Age of first pregnancy, years & 1.027 & 0.904 & to & 1.166 & 0.687 \\
Breastfeeding & 0.828 & 0.075 & to & 9.074 & 0.877 \\
Smoking & & & N.A. & & \\
Diabetes mellitus & & & N.A. & & \\
Lesion size, cm & 1.165 & 0.737 & to & 1.843 & 0.514 \\
Abscess formation & 2.571 & 0.545 & to & 12.139 & 0.233 \\
Multiple lesions & 1.591 & 0.279 & to & 9.066 & 0.601 \\
Skin ulcer or fistula & 11.692 & 1.302 & to & 105.028 & 0.028 \\
Symptom duration, weeks & 1.016 & 0.975 & to & 1.059 & 0.456 \\
Bilateral lesions & 4.320 & 0.851 & to & 21.929 & 0.078 \\
Extramammary manifestation & 2.857 & 0.601 & to & 13.586 & 0.187 \\
Corynebacterium infection & 0.857 & 0.147 & to & 4.999 & 0.864 \\
C-reactive protein, mg/dL & 1.874 & 1.139 & to & 3.084 & 0.013 \\
Methotrexate use & 4.400 & 0.911 & to & 21.248 & 0.065 \\
Surgery & 0.955 & 0.199 & to & 4.571 & $>0.900$ \\
Time to resolution, weeks & 1.015 & 0.993 & to & 1.038 & 0.171 \\
\hline
\end{tabular}

CI, confidence interval; N.A., not applicable.

\section{Discussion}

This study revealed that serum CRP and IL-6 levels served as biomarkers for disease severity in patients with IGM. Moreover, both serum CRP and IL-6 levels were associated with time to resolution significantly. Among the clinical features, serum CRP level was one of the risk factors for a longer time to resolution and recurrence in our analysis. These findings implied that serum CRP and IL-6 levels were useful biomarkers for evaluating the severity of IGM. The association between serum IL-6 level and clinical outcomes expanded the understanding of the mechanism of inflammation in IGM. To our knowledge, only a few studies have examined the association between biomarkers and clinical outcomes, and this is the first study to reveal the role of IL-6 and CRP in IGM.

As the potential sources of IL-6, epithelioid histiocytes, multinucleated giant cells, and $\mathrm{T}$ cells were found in the pathological study of IGM [22]. Furthermore, the percentage of circulating effector T cells was higher in IGM patients than HC [23]. In addition, IL-6 together with IL-23 and transforming growth factor- $\beta$ can induce $\mathrm{T}$ cell differentiation into $T$ helper $17\left(\mathrm{~T}_{\mathrm{H}} 17\right)$ cells. $\mathrm{T}_{\mathrm{H}} 17$ cells will produce proinflammatory cytokines, IL-17, and IL-22 [24]. Our findings were compatible with the findings of a previous study which demonstrated that higher serum IL-17 concentration was found in IGM patients compared to HC [14]. The other study showed that the serum concentration of IL-22 and IL-23 was higher in IGM patients compared to HC; however, there was no statistically significant difference in serum IL-17 concentration [13]. The increased synthesis of CRP is primarily induced by IL- 6 , and to a lesser degree by IL- $1 \beta$ and TNF- $\alpha$. A lower serum CRP level in patients with IGM compared to patients with breast cancer (median: $0.15 \mathrm{vs} .0 .56 \mathrm{mg} / \mathrm{dL}$; $p<0.001$ ) was reported in a previous study [15]. However, we found a higher serum CRP level (median: $1.80 \mathrm{mg} / \mathrm{dL}$ ) in patients with severe IGM. This discrepancy might be owing to the fact that the previous study did not take into account disease severity. The impact of breastfeeding on the prognosis of IGM is currently under investigation. A previous study indicated that the percentage of breastfeeding was higher in IGM patients with a longer time to resolution [25]. However, the treatment protocol was varied between the groups of different time to resolution. The same treatment protocol was applied to our cohort. After adjusting for other risk factors, we demonstrated that breastfeeding was associated with a 
shorter time to resolution. In contrast to the recent study, we did not find the association between the age of first live birth and time to resolution [26]. The mean age of first live birth of our cohort and the previous study were 31.1 and 21.6 years, respectively. This difference can lead to the inconsistency of association between age of first live birth and time to resolution. One possible explanation is that the influence of age of first live birth might be trivial due to longer exposure to hormone stimulation of mammary gland in our cohort.

An inflammatory biomarker, neutrophil-to-lymphocyte ratio (NLR), has been identified as a risk factor of recurrence in patients with IGM [27]. However, serum CRP level was not measured in the above study. The NLR represents the interaction between the innate and adaptive immune systems. Furthermore, the NLR has been known as a prognostic factor in cardiovascular disease and solid cancer $[28,29]$. Although the present study showed a numerical increase of NLR in IGM patients with recurrence, NLR and serum CRP level both were essential for evaluation of inflammation. Similar to our results, skin ulcer or fistula has been identified to be a risk factor for recurrence in the previous studies [30,31]. Therefore, we should be alert to the skin lesion of the breast in patients with IGM. Prompt treatment is required to prevent damage from persistent inflammation.

The results of the present study provided evidence for the association of dysregulated IL-6 production and disease severity in IGM. Our findings suggested a new link between the innate and adaptive immune systems in the complexity of IGM pathogenesis. In this study, elevated serum TNF- $\alpha$, IL-1 $\beta$, and IL- 6 levels indicated the involvement of activated innate immunity in patients with IGM. TNF- $\alpha$, IL- $1 \beta$, and IL- 6 are endogenous pyrogens and inducers of acute phase response [32]. On the other hand, elevated serum IL-2, IL-6, IL-12p70, and IL-17A levels supported the hypothesis of the aberrant T cell immunity in granuloma formation of IGM. IL-2 can induce T cell proliferation, and IL-12p70 and IL-6 can induce differentiation of CD4 $\mathrm{T}$ cells into the type 1 helper $\mathrm{T}\left(\mathrm{T}_{\mathrm{H}} 1\right)$ cells and $\mathrm{T}_{\mathrm{H}} 17$ cells, respectively [33]. $\mathrm{T}_{\mathrm{H}} 1$ and $\mathrm{T}_{\mathrm{H}} 17$ responses were both required in the development of granulomatous inflammation in tuberculosis and sarcoidosis [34,35]. However, the conflicting results of the $\mathrm{T}_{\mathrm{H}} 17$ response in IGM were observed in the aforementioned studies $[13,14]$. The findings of this study suggested that the $\mathrm{T}_{\mathrm{H}} 17$ response might be involved in the chronic inflammation in IGM. Further analyses are required to elucidate the relationship between T cell subsets and chronic inflammation in IGM.

The findings of this study suggested the association of serum CRP level and disease severity in IGM patients. Serum CRP measurement can be helpful not only in the assessment of disease severity but also in estimating time to resolution in patients with IGM. Patients with bilateral lesions were associated with time to resolution but not with disease severity. The disease severity might be underestimated in patients with bilateral lesions, who were assessed by a unilateral breast lesion. A careful assessment of the disease severity by physical examination and serum CRP level can provide useful information relating to the treatment of patients with bilateral lesions. Excessive cytokine production of IGM can be reduced by inhibition of inflammation. In a randomized controlled trial, numerical reduction of serum TNF- $\alpha$, IL-1 $\beta$, IL-2, and IL- 6 was found in IGM patients after treated with Chuang Ling Ye, which is a traditional Chinese herbal medicine compound composed of rhubarb, safflower, Abelmoschus manihot, and Terminalia chebula [36]. With the understanding of cytokine dysregulation in IGM, anti-cytokine therapies may be a promising treatment option to eliminate the inflammation in IGM.

TNF inhibitors, including etanercept and adalimumab, have been successfully used to treat patients with IGM refractory to systemic GC treatment $[9,12]$. However, there is no study regarding the use of other TNF inhibitors (infliximab, golimumab, certolizumab pegol) in the treatment of IGM. The pathogenic role of dysregulated IL-6 in rheumatoid arthritis, juvenile idiopathic arthritis, Castleman disease, giant cell arteritis, and cytokine release syndrome has been supported by the efficacy of IL-6-targeted therapies [24]. Biologics targeting IL-6 signaling might also alleviate the localized inflammatory response of IGM. Granulomatous mastitis can be one of the manifestations of giant cell arteritis [7]. 
Tocilizumab was the first anti-IL-6 receptor monoclonal antibody to be approved to treat giant cell arteritis by the FDA and EMA [37]. Sirukumab, an anti-IL-6 monoclonal antibody, has shown the efficacy in decreasing disease flares of giant cell arteritis in a phase 3 trial with early termination [38]. The effectiveness of IL-6-targeted therapies in the treatment of IGM might be a pioneering research agenda in further pilot studies. Anakinra (IL-1 receptor antagonist), ustekinumab (anti-IL-12/23p40 monoclonal antibody), and secukinumab (antiIL-17A monoclonal antibody) have demonstrated the effectiveness in the treatment of giant cell arteritis in case reports, case series, and non-controlled cohort studies [39-43]. Future studies are needed to investigate the potential therapeutic targets for anti-inflammation in IGM.

MTX was administered to IGM patients when exacerbation occurred during systemic GC dose reduction in our study. Consequently, MTX use was associated with a longer time to resolution. Combination therapy with systemic GC and MTX has been used in IGM patients with poor response to systemic GC alone [44]. Nevertheless, the effectiveness of MTX monotherapy in the treatment of IGM was demonstrated in recent studies [20,45]. The optimal therapeutic strategy for use of MTX in IGM patients remains to be delineated. Chronic low-grade inflammation is a hallmark of aging. In patients with breast cancer, serum CRP level is higher in the elderly compared to the younger group [46]. This study indicated that older age is associated with recurrence in IGM. The age-associated inflammatory state might participate in the complex mechanism of IGM recurrence. However, this finding needs to be confirmed in future studies.

The following limitations are noteworthy in the present study. First, the number of included patients was small because of the rarity of IGM. Only 11 patients and seven HC were biologically explored. A small number of HC can not reflect the true normal range of serum cytokine levels. Thus, the results of the comparison of serum cytokine levels between patients with IGM and HC should be interpreted with caution. Future studies with a larger sample size can help to provide robust evidence. However, we provided a novel perspective on the relationship between biomarkers and disease severity. This new evidence of cytokine dysregulation makes advances in the field of the immunopathology of IGM. Second, the serum cytokine levels of patients with IGM in the present study were lower than the studies mentioned above $[13,14,36]$. Furthermore, the serum cytokine levels were within the normal range in most of our patients. This discrepancy might be explained by the use of immunosuppressants in $87.8 \%$ of the patients with IGM in the present study. By contrast, the immunosuppressants were scarcely used in the previous studies $[13,14,36]$. The use of immunosuppressants should be taken into consideration while delineating the cytokine profiling in IGM. Third, the current classification of disease severity can not make an accurate assessment of disease activity [16]. A disease activity scoring system can improve risk stratification and monitoring of disease activity in patients with IGM. The association between serum CRP level and disease severity may help in the development of a practical scoring system. Last, the cytokine profiling of IGM can not explain the stimulation of serum IL-6 production. The production of IL-6 may be stimulated by IL-1 and Toll-like receptors [24]. The present study facilitates the exploration of upstream signaling pathways of serum IL-6 production in patients with IGM.

\section{Conclusions}

In conclusion, serum CRP and IL-6 levels served as biomarkers for disease severity and time to resolution in patients with IGM. The association between serum IL-6 level and clinical outcomes provides valuable insight into the mechanism of inflammation in IGM. Future studies need to investigate the interaction of IL-6 with other inflammatory biomarkers in the pathogenesis of IGM. 
Author Contributions: K.-J.L. Y.-M.H., and C.L. contributed to the study design, data collection, and drafted the manuscript. S.-C.H. conceptualized the research, designed the study, and approved the final version of the manuscript. C.-F.C. and C.-H.L. assisted with analysis, interpretation of the data, and revision of the manuscript. All authors have read and agreed to the published version of the manuscript.

Funding: This study was supported by grants from National Taiwan University Hospital (NTUH107-003899), Taipei, Taiwan.

Institutional Review Board Statement: The study was conducted according to the guidelines of the Declaration of Helsinki, and approved by the Institutional Review Board and Research Ethics Committees of National Taiwan University Hospital (201705097RINB).

Informed Consent Statement: Informed consent was obtained from all subjects involved in the study.

Data Availability Statement: All data presented in this study are available on demand from the corresponding author.

Acknowledgments: We are indebted to the Clinical Immunology and Transplantation Research Center, Department of Medical Research, National Taiwan University Hospital, Taipei, Taiwan for providing space and laboratory instruments for experiments.

Conflicts of Interest: The authors declare that there is no conflict of interest.

\section{References}

1. Kessler, E.; Wolloch, Y. Granulomatous mastitis: A lesion clinically simulating carcinoma. Am. J. Clin. Pathol. 1972, 58, 642-646. [CrossRef] [PubMed]

2. Tan, Q.T.; Tay, S.P.; Gudi, M.A.; Nadkarni, N.V.; Lim, S.H.; Chuwa, E.W.L. Granulomatous mastitis and factors associated with recurrence: An 11-year single-centre study of 113 patients in Singapore. World J. Surg. 2019, 43, 1737-1745. [CrossRef] [PubMed]

3. Martinez-Ramos, D.; Simon-Monterde, L.; Suelves-Piqueres, C.; Queralt-Martin, R.; Granel-Villach, L.; Laguna-Sastre, J.M.; Nicolau, M.J.; Escrig-Sos, J. Idiopathic granulomatous mastitis: A systematic review of 3060 patients. Breast J. 2019, 25, 1245-1250. [CrossRef] [PubMed]

4. Sheybani, F.; Naderi, H.R.; Gharib, M.; Sarvghad, M.; Mirfeizi, Z. Idiopathic granulomatous mastitis: Long-discussed but yet-to-be-known. Autoimmunity 2016, 49, 236-239. [CrossRef]

5. Prasad, S.; Jaiprakash, P.; Dave, A.; Pai, D. Idiopathic granulomatous mastitis: An institutional experience. Turk. J. Surg. 2017, 33, 100-103. [CrossRef] [PubMed]

6. Altintoprak, F.; Kivilcim, T.; Ozkan, O.V. Aetiology of idiopathic granulomatous mastitis. World J. Clin. Cases 2014, 2, 852-858. [CrossRef] [PubMed]

7. Goulabchand, R.; Hafidi, A.; Van de Perre, P.; Millet, I.; Maria, A.T.J.; Morel, J.; Quellec, A.L.; Perrochia, H.; Guilpain, P. Mastitis in autoimmune diseases: Review of the literature, diagnostic pathway, and pathophysiological key players. J. Clin. Med. 2020, 9 , 958. [CrossRef]

8. Lacambra, M.; Thai, T.A.; Lam, C.C.; Yu, A.M.; Pham, H.T.; Tran, P.V.; Law, B.K.; Van Nguyen, T.; Pham, D.X.; Tse, G.M. Granulomatous mastitis: The histological differentials. J. Clin. Pathol. 2011, 64, 405-411. [CrossRef] [PubMed]

9. Wang, S.T.; Lin, J.C.; Li, C.F.; Lee, Y.H. A successful case of etanercept used for idiopathic granulomatous mastitis. Breast J. 2019, 25, 343-345. [CrossRef]

10. Neel, A.; Hello, M.; Cottereau, A.; Graveleau, J.; De Faucal, P.; Costedoat-Chalumeau, N.; Rondeau-Lutz, M.; Lavigne, C.; Chiche, L.; Hachulla, E.; et al. Long-term outcome in idiopathic granulomatous mastitis: A western multicentre study. QJM 2013, 106, 433-441. [CrossRef]

11. Raj, N.; Macmillan, R.D.; Ellis, I.O.; Deighton, C.M. Rheumatologists and breasts: Immunosuppressive therapy for granulomatous mastitis. Rheumatology 2004, 43, 1055-1056. [CrossRef] [PubMed]

12. Cadena-Semanate, R.E.; Estrella-Tapia, L.F.; Contreras-Yametti, F.I.; Contreras-Yametti, J.E.; Salazar-Molina, R.D. Adalimumab in a patient with refractory idiopathic granulomatous mastitis: A case report. Breast J. 2021, 27, 99-102. [CrossRef] [PubMed]

13. Saydam, M.; Yilmaz, K.B.; Sahin, M.; Yanik, H.; Akinci, M.; Yilmaz, I.; Balas, S.; Azili, C.; Gulcelik, M.A. New findings on autoimmune etiology of idiopathic granulomatous mastitis: Serum IL-17, IL-22 and IL-23 levels of patients. J. Investig. Surg. 2020, 1-5. [CrossRef] [PubMed]

14. Koksal, H.; Vatansev, H.; Artac, H.; Kadoglou, N. The clinical value of interleukins-8, -10, and -17 in idiopathic granulomatous mastitis. Clin. Rheumatol. 2020, 39, 1671-1677. [CrossRef] [PubMed]

15. Yigitbasi, M.R.; Guntas, G.; Atak, T.; Sonmez, C.; Yalman, H.; Uzun, H. The role of interleukin-33 as an inflammatory marker in differential diagnosis of idiopathic granulomatous mastitis and breast cancer. J. Investig. Surg. 2017, 30, 272-276. [CrossRef]

16. Kaviani, A.; Vasigh, M.; Omranipour, R.; Mahmoudzadeh, H.; Elahi, A.; Farivar, L.; Zand, S. Idiopathic granulomatous mastitis: Looking for the most effective therapy with the least side effects according to the severity of the disease in 374 patients in Iran. Breast J. 2019, 25, 672-677. [CrossRef] [PubMed] 
17. Chirappapha, P.; Thaweepworadej, P.; Supsamutchai, C.; Biadul, N.; Lertsithichai, P. Idiopathic granulomatous mastitis: A retrospective cohort study between 44 patients with different treatment modalities. Ann. Med. Surg. 2018, 36, 162-167. [CrossRef]

18. Cetin, K.; Sikar, H.E.; Goret, N.E.; Rona, G.; Barisik, N.O.; Kucuk, H.F.; Gulluoglu, B.M. Comparison of topical, systemic, and combined therapy with steroids on idiopathic granulomatous mastitis: A prospective randomized study. World J. Surg. 2019, 43, 2865-2873. [CrossRef]

19. Lei, X.; Chen, K.; Zhu, L.; Song, E.; Su, F.; Li, S. Treatments for idiopathic granulomatous mastitis: Systematic review and meta-analysis. Breastfeed. Med. 2017, 12, 415-421. [CrossRef] [PubMed]

20. Postolova, A.; Troxell, M.L.; Wapnir, I.L.; Genovese, M.C. Methotrexate in the treatment of idiopathic granulomatous mastitis. J. Rheumatol. 2020, 47, 924-927. [CrossRef] [PubMed]

21. Heinze, G.; Wallisch, C.; Dunkler, D. Variable selection-A review and recommendations for the practicing statistician. Biom. J. 2018, 60, 431-449. [CrossRef] [PubMed]

22. Erhan, Y.; Veral, A.; Kara, E.; Ozdemir, N.; Kapkac, M.; Ozdedeli, E.; Yilmaz, R.; Koyuncu, A.; Erhan, Y.; Ozbal, O. A clinicopthologic study of a rare clinical entity mimicking breast carcinoma: Idiopathic granulomatous mastitis. Breast 2000, 9, 52-56. [CrossRef] [PubMed]

23. Ucaryilmaz, H.; Koksal, H.; Emsen, A.; Kadoglou, N.; Dixon, J.M.; Artac, H. The role of regulatory T and B cells in the etiopathogenesis of idiopathic granulomatous mastitis. Immunol. Investig. 2020, 1-11. [CrossRef]

24. Garbers, C.; Heink, S.; Korn, T.; Rose-John, S. Interleukin-6: Designing specific therapeutics for a complex cytokine. Nat. Rev. Drug Discov. 2018, 17, 395-412. [CrossRef]

25. Al-Khaffaf, B.; Knox, F.; Bundred, N.J. Idiopathic granulomatous mastitis: A 25-year experience. J. Am. Coll. Surg. 2008, 206, 269-273. [CrossRef]

26. Davis, J.; Cocco, D.; Matz, S.; Hsu, C.H.; Brown, M.J.; Lee, J.; Bouton, M.E.; Caruso, D.M.; Komenaka, I.K. Re-evaluating if observation continues to be the best management of idiopathic granulomatous mastitis. Surgery 2019, 166, 1176-1180. [CrossRef]

27. Cetinkaya, O.A.; Celik, S.U.; Terzioglu, S.G.; Eroglu, A. The predictive value of the neutrophil-to-lymphocyte and platelet-tolymphocyte ratio in patients with recurrent idiopathic granulomatous mastitis. Eur. J. Breast Health 2020, 16, 61-65. [CrossRef]

28. Kim, S.; Eliot, M.; Koestler, D.C.; Wu, W.C.; Kelsey, K.T. Association of neutrophil-to-lymphocyte ratio with mortality and cardiovascular disease in the Jackson Heart Study and modification by the Duffy antigen variant. JAMA Cardiol. 2018, 3, 455-462. [CrossRef]

29. Templeton, A.J.; McNamara, M.G.; Seruga, B.; Vera-Badillo, F.E.; Aneja, P.; Ocana, A.; Leibowitz-Amit, R.; Sonpavde, G.; Knox, J.J.; Tran, B.; et al. Prognostic role of neutrophil-to-lymphocyte ratio in solid tumors: A systematic review and meta-analysis. J. Natl. Cancer Inst. 2014, 106, dju124. [CrossRef]

30. Azizi, A.; Prasath, V.; Canner, J.; Gharib, M.; Sadat Fattahi, A.; Naser Forghani, M.; Sajjadi, S.; Farhadi, E.; Vasigh, M.; Kaviani, A.; et al. Idiopathic granulomatous mastitis: Management and predictors of recurrence in 474 patients. Breast J. 2020, 26, $1358-1362$. [CrossRef]

31. Yilmaz, T.U.; Gurel, B.; Guler, S.A.; Baran, M.A.; Ersan, B.; Duman, S.; Utkan, Z. Scoring idiopathic granulomatous mastitis: An effective system for predicting recurrence? Eur. J. Breast Health. 2018, 14, 112-116. [CrossRef]

32. Kany, S.; Vollrath, J.T.; Relja, B. Cytokines in inflammatory disease. Int. J. Mol. Sci. 2019, 20, 6008. [CrossRef]

33. Chatzileontiadou, D.S.M.; Sloane, H.; Nguyen, A.T.; Gras, S.; Grant, E.J. The many faces of CD4(+) T cells: Immunological and structural characteristics. Int. J. Mol. Sci. 2020, 22, 73. [CrossRef]

34. Walzl, G.; Ronacher, K.; Hanekom, W.; Scriba, T.J.; Zumla, A. Immunological biomarkers of tuberculosis. Nat. Rev. Immunol. 2011, 11, 343-354. [CrossRef]

35. Grunewald, J.; Grutters, J.C.; Arkema, E.V.; Saketkoo, L.A.; Moller, D.R.; Muller-Quernheim, J. Sarcoidosis. Nat. Rev. Dis. Primers 2019, 5, 45. [CrossRef]

36. Xue, J.X.; Ye, B.; Liu, S.; Cao, S.H.; Bian, W.H.; Yao, C. Treatment efficacy of Chuang Ling Ye, a traditional chinese herbal medicine compound, on idiopathic granulomatous mastitis: A randomized controlled trial. Evid. Based. Complement. Alternat. Med. 2020, 2020, 6964801. [CrossRef]

37. Choy, E.H.; De Benedetti, F.; Takeuchi, T.; Hashizume, M.; John, M.R.; Kishimoto, T. Translating IL-6 biology into effective treatments. Nat. Rev. Rheumatol. 2020, 16, 335-345. [CrossRef]

38. Schmidt, W.A.; Dasgupta, B.; Luqmani, R.; Unizony, S.H.; Blockmans, D.; Lai, Z.; Kurrasch, R.H.; Lazic, I.; Brown, K.; Rao, R. A multicentre, randomised, double-blind, placebo-controlled, parallel-group study to evaluate the efficacy and safety of sirukumab in the treatment of giant cell arteritis. Rheumatol. Ther. 2020, 7, 793-810. [CrossRef]

39. Deshayes, S.; Ly, K.H.; Rieu, V.; Maigne, G.; Silva, N.M.; Manrique, A.; Monteil, J.; de Boysson, H.; Aouba, A. French Study Group for Large Vessel Vasculitis (GEFA). Steroid-sparing effect of anakinra in giant-cell arteritis: A case series with clinical, biological and iconographic long-term assessments. Rheumatology 2021. [CrossRef]

40. Conway, R.; O’Neill, L.; O’Flynn, E.; Gallagher, P.; McCarthy, G.M.; Murphy, C.C.; Veale, D.J.; Fearon, U.; Molloy, E.S. Ustekinumab for the treatment of refractory giant cell arteritis. Ann. Rheum. Dis. 2016, 75, 1578-1579. [CrossRef]

41. Conway, R.; O’Neill, L.; Gallagher, P.; McCarthy, G.M.; Murphy, C.C.; Veale, D.J.; Fearon, U.; Molloy, E.S. Ustekinumab for refractory giant cell arteritis: A prospective 52-week trial. Semin. Arthritis Rheum. 2018, 48, 523-528. [CrossRef] [PubMed]

42. Matza, M.A.; Fernandes, A.D.; Stone, J.H.; Unizony, S.H. Ustekinumab for the treatment of giant cell arteritis. Arthritis Care. Res. 2020. [CrossRef] 
43. Rotar, Z.; Tomsic, M.; Hocevar, A. Secukinumab for the maintenance of glucocorticoid-free remission in a patient with giant cell arteritis and psoriatic arthritis. Rheumatology 2018, 57, 934-936. [CrossRef]

44. Freeman, C.M.; Xia, B.T.; Wilson, G.C.; Lewis, J.D.; Khan, S.; Lee, S.J.; Lower, E.E.; Edwards, M.J.; Shaughnessy, E.A. Idiopathic granulomatous mastitis: A diagnostic and therapeutic challenge. Am. J. Surg. 2017, 214, 701-706. [CrossRef] [PubMed]

45. Haddad, M.; Sheybani, F.; Arian, M.; Gharib, M. Methotrexate-based regimen as initial treatment of patients with idiopathic granulomatous mastitis. Breast J. 2020, 26, 325-327. [CrossRef] [PubMed]

46. Berben, L.; Floris, G.; Kenis, C.; Dalmasso, B.; Smeets, A.; Vos, H.; Neven, P.; Antoranz Martinez, A.; Laenen, A.; Wildiers, H.; et al. Age-related remodelling of the blood immunological portrait and the local tumor immune response in patients with luminal breast cancer. Clin. Transl. Immunol. 2020, 9, e1184. [CrossRef] 